\title{
CASTE AND THE JAJMANI SYSTEM IN INDIA
}

$I^{\mathrm{N}}$ $\mathrm{N}$ works about caste it is rare to find an analysis of how the different groups interact with one another in the production and exchange of goods and services. William H. Wiser, in his book "The Hindu Jajmani System", described how goods and services are exchanged in a rural Indian village and analysed jajmani relations as a system. Knowledge of this jajmani system is essential for an understanding of the economic aspects of caste in rural India; its methods of working have been investigated and described by Prof. Oscar Lewis and Dr. V. Barnouw (Sci. Mon., 83, No. 2 ; August 1956).

Under the system each caste group within a village is expected to give certain standardized services to the families of other castes. A khati (carpenter), for example, repairs tools, while a nai (barber) cuts hair ; but they do not necessarily perform these services for everyone. Each man works for a particular family or group of families with which he has hereditary ties. His father worked for the same families before him, and his son will continue to work for them, the occupation or service being determined by caste. The family or family-head served by an individual is known as his jajman, while the man who performs service is known as the jajman's kamin or kam karne-wala (literally, worker). These are the terms used in north-western India; where the system prevails in other parts of India other terms may be used.

It is a characteristic of the jajmani system to operate without much exchange of money. For it is not an open-market economy, and the ties between jajman and kamin are not like those of employer and employee in a capitalistic system. The jajman compensates his kamins for their work through periodic payments in cash or grain, made throughout the year on a daily, monthly or bi-yearly basis.
Kamins may also receive benefits such as free food, clothing, and residence site, and the use of certain tools and raw materials. These concessions represent the strength of the system and are more important than the monetary payments. Despite the increased use of money in recent years, the peasants tend to prefer grain payments to cash, since grain prices have risen so enormously in the past decade.

There is evidence that the jajmani system exists in eastern Uttar Pradesh, parts of Malabar and Cochin, the Mysore District, Tanjore, Hyderabad, Gujarat and the Punjab.

A major function of the jajmani system is to assure a stable labour supply for the dominant agricultural caste in a particular region by limiting the mobility of the lower castes, especially those who assist in agricultural work. If a kamin leaves the village, he must get someone to take his place, usually a member of the same joint family. This does not usually involve sale, and the jajman is not likely to object, as long as the position is filled. Such transfers are rare, the kamins having valued rights and advantages which make them hesitate to move. Moreover, the community may put pressure on an individual to make him stay.

Jajn ani rights, however, which link an individual to certain families, may be regarded as a form of property passing from father to son. Like land property, it is equally apportioned among brothers when they separate.

The widely held view that the caste system is crumbling rapidly in India is not borne out by examination. Although the jajmani system is tending to decline, this will not necessarily be followed by an automatic or speedy disintegration of the caste system. Instead, caste may continue to take on new functions and manifestations.

\section{CAPILLARY FILTERS OF KNOWN AND ADJUSTABLE PORE-SIZE}

\section{BY LEV AKOBJANOFF}

Institute of Engineering Research, University of California, Berkeley 4, California

$\mathrm{R}$ ODS of even thickness, when closely packed in parallel arrangement, produce a bundle of straight capillaries, with lumen corresponding approximately to one-sixth of the rod diameter. A possible use of such capillaries is in filtration, for example, by connecting an element of the kind shown in Fig. 1 to a syphon or some other suction system. Capillary filters of such structure are characterized by pores, which are (1) uniform, (2) of known size, (3) adjustable by more or less tightening the outer press. These three features have not been realized hitherto in any type of filter, in spite of considerable efforts in many instances ${ }^{1}$. Besides filtration, they open possibilities in other fractionations by size, for example, in sieving, diffusion, etc.

Among the materials which can be used in manufacturing capillary systems of the above kind, artificial textile fibres are of importance. Table 1 gives some characteristics of a few synthetic fibrillæ.

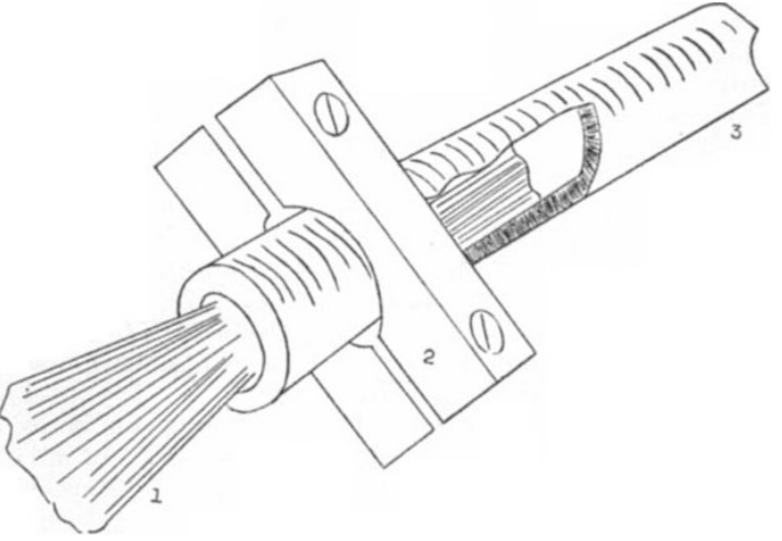

Fig. 1. (1) Rods and capillaries; (2) press ; (3) plastic tubing 